\title{
0 percurso da linha do cuidado sob a perspectiva das doenças crônicas não transmissíveis
}

Deborah Carvalho Malta ${ }^{1}$

Emerson Elias Merhy²

MALTA, D.C.; MERHY, E.E. The path of the line of care from the perspective of nontransmissible chronic diseases. Interface - Comunic., Saude, Educ., v.14, n.34, p.593-605, jul./set. 2010.

This study characterizes the line of care from the perspectives of micro and macropolicies and management. The example of chronic Non-Communicable Diseases - (NCD) is taken because of their magnitude and characteristics: long-term diseases requiring intense action from caregivers, therapeutic projects, access to services and integrated actions. The study discusses the perspective of the line of care centered on the field of users' needs and presupposes the existence of a caregiver, use of soft technologies, adequacy of therapeutic projects, existence of service networks that support the actions needed, access to healthcare resources available and actions regarding social determinants and the regulatory process. The development of promotion, prevention, surveillance and care policies for CNTDs is discussed, bringing in actions within the fields of micro and macropolicies and including interventions relating to social determinants, legislation, technologies and tools.

Keywords: Line of care. Autonomy. Micropolicy. Healthcare work. Chronic Non-Communicable Diseases.
Este trabalho caracteriza a linha do cuidado (LC) segundo as perspectivas micro e macropolíticas ou de gestão. Toma-se o exemplo das Doenças Crônicas Não Transmissíveis (DCNT), pela sua magnitude, e suas características: doença de longa duração, demandando intensa atuação de cuidadores, projetos terapêuticos, acesso aos serviços e ações integradas. O trabalho discute a perspectiva da LC centrada no campo de necessidades dos usuários e pressupõe a existência do cuidador, uso da tecnologia leve, projeto terapêutico adequado, existência da rede de serviços que suporte as ações necessárias, o acesso aos recursos assistenciais disponíveis, além da atuação nos determinantes sociais e no processo regulatório. Discute-se o desenvolvimento de políticas de promoção, prevenção, vigilância e assistência de DCNT, articulando ações no campo da micropolítica e macropolítica, integrando intervenção nos determinantes sociais, legislação, tecnologias e instrumentos.

Palavras-chave: Linha do cuidado.

Autonomia. Micropolítica. Trabalho em saúde. Doenças crônicas não transmissíveis. 1Escola de Enfermagem,
Universidade Federal de
Minas Gerais. Secretaria
de Vigilância em Saúde,
Coordenação geral de
Doenças e Agravos
Não Transmissíveis,
Ministério da Saúde.
SAF SUL, Trecho 2,
Lote 5 e 6, Bloco F,
Torre I, Ed. Premium,
sala 14 T. Brasília, DF,
Brasil. 70.070-600.
dcmalta@uol.com.br
2 Professor visitante,
Universidade Federal do
Rio de Janeiro. 


\section{Introdução}

O setor saúde vive uma crise na forma de se produzir saúde, induzindo o modelo produtor de procedimentos, ou modelo médico hegemônico (Cecílio, 1994; Merhy, Cecílio, Nogueira, 1992; Donangelo, Ferreira, 1976). A assistência à saúde é centrada no ato prescritivo que produz o procedimento, não sendo consideradas as determinações do processo saúde-doença centradas nos determinantes sociais ambientais e relacionadas às subjetivações, singularizantes, valorizando apenas as dimensões biológicas.

Este formato produz custos elevados e crescentes, pois utiliza, como insumos principais, os recursos tecnológicos centrados em exames e medicamentos (tecnologias duras), como se estes tivessem um fim em si mesmo e fossem capazes de restabelecer a saúde por si só. São produzidos atos desconexos sem uma intervenção articulada e cuidadora, reduzindo-se a eficácia da assistência prestada (Malta et al., 2004).

Para se repensar novas modelagens assistenciais, assentadas em diretrizes como a integralidade do cuidado, há que se aprofundar o debate sob novos fundamentos teóricos, particularmente sobre a natureza do processo de trabalho, sua micropolítica e importância na compreensão da organização da assistência à saúde (Malta et al., 2004). Torna-se necessário ainda repensar o processo saúdedoença, quanto aos seus determinantes e condicionantes, e a intervenção em toda a cadeia de produção de saúde, desde a promoção, prevenção, vigilância, assistência e reabilitação. Neste sentido, a linha do cuidado (LC) passa a ser desenhada também no campo da gestão, articulando intervenção nos determinantes sociais, em medidas de regulação e legislação, equacionando-se tecnologias, instrumentos, dentre outros, capazes de impactarem o processo saúde-doença, porém partindo do lugar do singular no ato do cuidado, que só o trabalho vivo pode dar conta. Desta forma, a atuação na macro e micropolítica deveria ocorrer de forma articulada, buscando os melhores resultados. $O$ essencial é a perspectiva da construção do cuidado centrada nos usuários e suas necessidades, e não de um modelo que atenda aos interesses do mercado (Malta et al., 2004).

Frente ao quadro atual de transição epidemiológica e demográfica com a predominância das doenças crônicas não transmissíveis (DCNT) e a ampliação da população de idosos, cresce a demanda por agregação de tecnologias (Malta et al., 2006). Torna-se fundamental repensar o modelo de assistência praticado, priorizando os atos cuidadores e a autonomia dos sujeitos.

O atual trabalho buscará analisar os desafios na construção da LC das DCNT segundo as perspectivas: micro e macropolítica ou da gestão.

\section{Metodologia}

Buscar-se-á, neste ensaio, apoiar-se na literatura quanto ao tema da LC, em especial o cuidado relacionado às DCNT. Foram realizadas buscas usando-se os seguintes descritores: linha do cuidado, doenças crônicas não transmissíveis, processo de trabalho em saúde, micropolítica e macropolítica.

Foram descritos os marcos conceituais da LC, na sua perspectiva macro e micropolítica. Em relação à primeira, foram identificados os seguintes aspectos: a) organização da vigilância e da informação em saúde; b) comunicação em saúde; c) medidas intersetoriais, legislação, regulação; d) organização da rede de serviços; e) identificação de grupos de risco e os protocolos como ferramentas. Na perspectiva da micropolítica e o processo de trabalho em saúde: a) atuação da equipe na coordenação do cuidado; b) vinculação e responsabilização do cuidador; c) busca da produção da autonomia do usuário.

\section{A concepção de LC}

Segundo Merhy e Cecílio (2003), o desenho da LC entende a produção da saúde de forma sistêmica, a partir de redes macro e microinstitucionais, em processos extremamente dinâmicos, nos quais está associada a imagem de uma linha de produção voltada ao fluxo de assistência ao beneficiário, centrada em seu campo de necessidades. 
A concepção da LC parte da missão institucional do estabelecimento/serviço de saúde, provendo mecanismos que garantam o cuidado (Cecílio, 1997). A LC é alimentada por recursos/insumos que expressam as tecnologias a serem consumidas pelos usuários durante o processo de assistência ao beneficiário, funcionando de forma sistêmica e operando vários serviços. Esta tem início na entrada do usuário em qualquer ponto do sistema que opere a assistência: seja no atendimento domiciliar, na equipe de saúde da família/atenção básica, em serviços de urgência, nos consultórios, em qualquer ponto onde haja interação entre o usuário e o profissional de saúde. A partir deste lugar de entrada, abre-se um percurso que se estende, conforme as necessidades do beneficiário, por serviços de apoio diagnóstico e terapêutico, especialidades, atenção hospitalar e outros (Malta et al., 2004; Merhy, Cecílio, 2003).

A produção da saúde implica formatos institucionais que articulam respostas macro e microinstitucionais (Merhy, Cecílio, 2003), ou seja, para equacionar o caminhar na LC, ordena-se tanto o processo de trabalho em saúde, quanto demandas de organização do sistema de saúde e suas interfaces.

\section{LC sob a perspectiva da micropolítica}

A perspectiva de organização da LC pressupõe-se a partir de um conceito simples, mas de difícil consecução, ou seja, a responsabilização do profissional e do sistema pela saúde do usuário. Parece ser simples esta conclusão, entretanto ela se encontra distante da prática cotidiana. O que se busca é potencializar o trabalho cuidador, no qual o profissional, ao se relacionar com o usuário, no momento da assistência, ou "no espaço intercessor", que é o espaço do encontro entre o usuário e o profissional de saúde, libere "trabalho vivo", em ato, neste momento singular e "cuidador" (Malta, Merhy, 2003). Este espaço relacional abre possibilidades de mudanças e de atos criativos, tornando-se um momento especial, portador de forças "instituintes" (Merhy, 2002; Baremblit, 1996). A potencialidade desse encontro pode ser "amordaçada" em função do modelo de assistência praticado e dos seus pressupostos. Poderíamos afirmar que os "espaços intercessores" podem ser preenchidos pela "voz" do profissional de saúde e pela "mudez" do usuário. Essa relação em saúde deveria ser não "objetal", comandada pelo autoritarismo do profissional, mas do tipo "interseção-partilhada", na qual acontecessem trocas, compartilhamentos, pela disponibilidade do profissional em liberar saberes e atos cuidadores, e pelo desejo do usuário em restabelecer sua autonomia (Malta et al., 2004; Merhy, 2002).

Torna-se chave o deslocamento do processo assistencial atual, centrado em procedimentos fragmentados, por outros processos, que se pautem pela responsabilização, vinculação e o cuidado.

Outro elemento consiste na perspectiva de criar um projeto terapêutico adequado a cada usuário na sua singularidade. Este tema implica um fluxo contínuo, monitorado, e controlado pelos atores que figuram como "gestores do cuidado", ou "cuidadores", encadeado em uma intensa rede de conversação na qual o centro da sua lógica é o processo de produção do cuidado pelos vários encontros que esse exige entre trabalhadores de saúde e o usuário.

Busca-se, ainda, a autonomia dos sujeitos no seu modo de viver e caminhar, autonomizando o usuário, provendo informações, suporte, que possam favorecer as suas escolhas responsáveis, que garantam maior qualidade de vida e independência dos atos de saúde.

\section{LC sob perspectiva da macropolítica ou da gestão}

O apoio e o investimento dos gestores em processos de gestão coletivos e participativos implica a corresponsabilidade entre os atores envolvidos no ato de cuidar. A efetivação da LC depende da determinação e apoio dos gestores, sejam públicos ou privados, na garantia do caminhar pela LC, equacionando os fluxos micro da LC com os macroprocessos. Os gestores controlam serviços e recursos assistenciais e são responsáveis pelo atendimento dos usuários, desde a sua entrada no sistema de saúde, garantindo o acesso aos serviços, recursos necessários e qualificação das respostas às suas necessidades em saúde (Vasconcelos, 2008; Franco, Magalhães Júnior, 2003).

Intervir na macropolítica passa por atuar nos determinantes sociais, buscando articulações intersetoriais, mudanças na legislação, atuação na regulação, no financiamento das ações, na rede de serviços, na organização da vigilância e informação em saúde. Além da construção de uma forte lógica 
da gestão, na qual o cuidado produzido é um processo que possibilita a oportunidade de colocar os seus construtores em reflexão e aprendizagem, bem como inserir a gestão em análise.

A LC se completa na medida em que macroprocessos se articulam com os microprocessos. Entretanto sempre ocorre o risco: da ruptura ou fragmentação da LC, pois são muitas variáveis a serem garantidas e nem sempre elas se entrelaçam. Pode-se correr o risco de tentar capturá-la sob a dura forma de agir da programação em saúde, que não consegue atuar nos modos singulares como cada um se apresenta no campo do cuidado, burocratizando as linhas de cuidado a ponto de elas existirem sem a necessidade do usuário real - só o imaginário protocolado é que tem presença - enfraquecendo os próprios programas como tecnologias de cuidado válidos em várias situações (Freire, 2005).

\section{A LC das DCNT}

A escolha da LC das DCNT se justifica pela magnitude destas doenças, a crescente morbimortalidade, pelos custos que agrega e por gerar eventos contínuos/crônicos e que, com frequência, se agudizam, especialmente quando não bem cuidados, podendo ser um tema analisador das situações de fragmentação da LC.

As DCNT se caracterizam por uma etiologia incerta, múltiplos fatores de risco, longos períodos de latência, curso prolongado, origem não infecciosa e por estarem associadas a deficiências e incapacidades funcionais (World Health Organization - WHO, 2005). Nas últimas décadas, as DCNT passaram a liderar as causas de óbito no Brasil, quase $64 \%$ das mortes, ultrapassando, em muito, as taxas de mortalidade por doenças infecciosas e parasitárias (DIP) (Malta et al., 2006). Processa-se, no Brasil, a transição epidemiológica, demográfica e nutricional, aumentando a carga de DCNT, a população de idosos e o acúmulo de pessoas obesas e com sobrepeso, bem como com outros fatores de risco que predispõem ainda mais ao aumento da morbimortalidade por DCNT. Torna-se urgente a articulação de políticas e programas voltados para o enfrentamento desta realidade, bem como aprofundar sobre o cuidado que tem sido dispensado aos portadores de DCNT nos serviços de saúde, quer sejam públicos, ou privados (Malta et al., 2006).

O aumento da DCNT afeta todos os países, ricos ou pobres, todas as classes sociais e sexos. Estimase que 35 milhões de mortes ocorrem anualmente, levando a OMS a estabelecer metas para sua redução (WHO, 2005).

\section{A LC de DCNT sob a perspectiva dos macroprocessos}

\section{a) A organização da vigilância e da informação em saúde}

Do ponto de vista da vigilância, é necessária a sua organização, agregando informações sobre as necessidades da população, seja sobre morbimortalidade, seja sobre os fatores de risco (atividade física, alimentação, tabagismo, uso abusivo de álcool, obesidade, hipertensão, diabetes), visando definir vulnerabilidade e riscos, e melhor ajustar as estratégias de intervenção, e alimentar a caixa de ferramenta dos cuidadores, para terem opções diante dos processos de cuidado com que vão se defrontar, mas sem estabelecer receitas. Nesse sentido, o uso ou não de certas opções só se adequa ao trabalho vivo, em ato; inclusive por considerar que nesse lugar está em aberto o inventar, o atuar fora das próprias ferramentas, com outros recursos que não precisam estar dados a priori. Uma das questões que devemos considerar é o fracasso intenso que as propostas de cuidado formatadas a priori têm tido junto a pessoas portadoras de diabetes e hipertensão, entre outras, por não conseguirem chegar ao singular de cada um, por imporem a priori olhares e fazeres que não têm nada a ver com o usuário real que está ali no trabalho de saúde que está se processando.

\section{b) Comunicação em saúde}

Torna-se fundamental disseminar essas informações e incentivar as ações, bem como utilizar os meios de comunicação, como estratégia de mobilização e engajamento da comunidade, buscando incentivar iniciativas de advocacy voltadas para divulgação, sensibilização e convencimento da 
comunidade. Torna-se importante a formação de redes sociais e o empoderamento da comunidade, bem como a sua responsabilização e participação na definição das ações a serem desenvolvidas (Brasil, 2008; WHO, 2005).

c) Medidas intersetoriais, legislação, regulação

A abordagem aos formuladores de políticas públicas implicaria a adoção e formulação de políticas e ações de saúde pública abrangentes e integradas, apoiadas em ações intersetoriais, levando em conta os vários ciclos da vida, as condições e necessidades locais. Para a implementação de políticas específicas devem ser definidas: estratégias para o financiamento das ações, proposição de medidas legislativas e regulatórias, além de ações sobre o ambiente urbano e meios de transporte que facilitem modos de viver a vida de modo mais intenso e implicado com a sua própria produção, e não a da morte (Merhy, 2007).

Tomemos, como exemplo, a redução do sedentarismo, que necessita de medidas essenciais para o aumento dos níveis de atividade física populacionais, como: a criação de espaços públicos adequados e seguros, a organização do espaço urbano quanto às possibilidades de deslocamento a pé e/ou em bicicletas, investindo em segurança pública, iluminação, dentre outros aspectos do planejamento urbano. Desta forma, desloca-se do foco exclusivo no desejo e decisão individuais de envolver-se em práticas corporais para a análise das condições que facilitam ou não a eleição de um modo de viver mais ou menos sedentário (Malta et al., 2009).

Da mesma forma, o acesso à alimentação implica não somente escolhas individuais, mas, fundamentalmente, políticas públicas integradas, desde: ações educativas; acesso à merenda escolar saudável; incentivo à produção, distribuição e comercialização de alimentos adequados; legislação oportuna quanto aos teores de sal, açúcar, gorduras trans; informações nutricionais em produtos industrializados; regulação do conteúdo das propagandas que atingem públicos específicos, como, por exemplo, as crianças (Brasil, 2008).

No caso do tabagismo, já existem evidências da importância da ação do Estado, seja na regulação da propaganda, controle dos pontos de venda, taxação de produtos do cigarro, dentre outros. Estas medidas instaladas no Brasil, na última década, resultaram em evidente redução da venda de produtos, declínio na prevalência de tabagistas no país, bem como nas taxas de mortalidade por câncer de pulmão entre homens abaixo de 65 anos (Malta et al., 2007; Monteiro et al., 2007).

As abordagens populacionais são universais e de grande abrangência, por isto torna-se central a construção de políticas públicas centradas em diretrizes de promoção à saúde, que abordem as questões relativas aos determinantes sociais, possibilitando o acesso dos cidadãos a escolhas mais saudáveis.

\section{d) Organização da rede de serviços}

Outro foco a se atuar nas respostas aos portadores de DCNT consiste na melhoria dos serviços de saúde. Nesta dimensão, está a importância de se integrarem os diversos níveis de atenção do sistema de saúde, onde acesso e resolutividade são palavras-chave e onde ganham espaço as LC.

A integralidade do cuidado só pode ser obtida em rede. Deve haver algum grau de integralidade "focalizada", mesmo que não seja suficiente, quando uma equipe, em um serviço de saúde, por meio de uma boa articulação de suas práticas, consegue escutar e atender, da melhor forma possível, as necessidades de saúde (Merhy, Cecilio, 2003). Cada serviço pode ser repensado como um componente fundamental da integralidade do cuidado, como uma "estação" no circuito que cada indivíduo percorre para obter a integralidade de que necessita. Cabe o desafio de "conectar" essas redes assistenciais, de forma mais adequada à rede de serviços de saúde.

Todas as "estações" da rede de serviços são essenciais para a LC; para o hipertenso ou o portador de qualquer doença crônica, é essencial acessar a rede "básica", ser bem acolhido, estar vinculado a uma equipe, ser incentivado a participar de grupos que lhe façam sentido, e não preleções que não Ihe estimulam a rever nada no seu modo de viver, ou seja, grupos que consigam, junto com ele, operar a criação de novos sentidos para o viver. Além disto, este usuário poderá necessitar de apoio diagnóstico, terapêutico e de cuidados especializados, articulados e concatenados de forma a remetêlo de volta ao cuidador, após o percurso em cada "estação de cuidado". Espera-se, com isto, evitar o 
uso dos serviços de urgência e dos serviços hospitalares. Entretanto, isto pode ocorrer e, no momento em que isto acontecer, o hospital também pode ter papel fundamental na ligação da rede, por exemplo: o momento de alta de cada paciente poderia ser um momento privilegiado para se produzir a continuidade do processo de cuidado na rede básica onde o usuário já está conectado, ao invés de simplesmente lhe fornecer uma contrarreferência sem compromisso, apenas de forma burocrática. $O$ período da internação pode, inclusive, ser aproveitado para apoiar o paciente na direção de conquistar uma maior autonomia e na reconstrução de seu modo de andar a vida. O cuidador da atenção básica poderia, inclusive, participar desse acompanhamento, contribuindo na condução terapêutica no âmbito hospitalar, criando ligações potentes entre as equipes das várias estações, discutindo condutas, protocolos, fluxos e reduzindo a demanda de novos pacientes para o serviço hospitalar. Isso pode ser construído pela gestão, como espaço articulado da educação permanente em rede.

A adoção das LC como organizadoras do trabalho em saúde pressupõe a vinculação das equipes de saúde com a população da região de saúde em que se situam e agem, sua territorialização. Portanto, as dimensões macropolítica e micropolítica se entrelaçam e se complementam.

Entretanto é fundamental se processarem mudanças no processo de trabalho em saúde, buscando a qualidade dos serviços, capacitação dos profissionais, insumos estratégicos. Cabe ainda, aos gestores, a organização dos serviços de saúde de forma a integrar os diversos níveis de atenção do sistema de saúde, onde acesso e resolutividade são palavras-chave e onde ganham espaço para o equacionamento das LC.

\section{e) Identificação de grupos de risco e os protocolos como ferramentas}

Uma das maneiras de organizar o processo de atenção é pensar e planejar intervenções nos chamados grupos de risco, onde a atenção se volta para grupos populacionais, gerando ações mais efetivas. Mapear grupos prioritários para atuação é algo muito útil na abordagem das DCNT. Sem, no entanto, desconsiderar a oferta de portas de acesso para todos que procurem por serviços de saúde, pois, se é necessário eleger grupos prioritários, não há como transformá-los em exclusivos em uma ótica que se confunda com estratégias focalizantes. Assim, operar sobre grupos específicos tem de constituir uma das muitas estratégias de cuidado a ser ofertada, e, ainda mais importante, considerar a singularidade e autonomia dos sujeitos na definição das opções terapêuticas adequadas ao seu contexto de vida.

Embora as diretrizes para intervenção no curso das DCNT estejam estabelecidas por consensos científicos, não constituem informações rotineiramente manipuladas pelas equipes de saúde, gerando cuidados incompletos e muitas vezes ineficazes, o que termina por colocar em risco a vida dos pacientes, além de sobrecarregar financeira e operacionalmente o sistema.

$\mathrm{Na}$ organização dos serviços de saúde existem muitos desafios a serem alcançados, desde a compreensão das LC como organizadoras do trabalho, a vinculação das equipes de saúde com a população da região de saúde em que se situam e agem, responsabilizando-se pelo usuários, seja nos desdobramentos, seja na definição do manejo adequado, na definição de protocolos clínicos que incluam terapêutica medicamentosa adequada e procedimentos adaptados às especificidades do usuário, suas necessidades e singularidade. A definição de protocolos deve contemplar a análise de custo efetividade, os programas e recomendações já existentes, bem como definir insumos estratégicos e estratégias diagnósticas disponíveis e em utilização nas diversas regiões do país. Torna-se importante, para a qualidade da assistência, embasar-se na melhores evidências científicas disponíveis. Os protocolos devem buscar a eficiência, a racionalidade, bem como adequar-se às necessidades, valores e preferências do usuário, constituindo-se em elemento essencial para um bom cuidado com a DCNT, a adesão do usuário ao programa proposto.

Não podemos nos esquecer de colocar os próprios protocolos em análise, pois os mesmos, por serem construídos muitas vezes por consenso científico, estão aí como ferramentas, e não como receitas. O que interessa neles é que o cuidador possa perguntar que tipo de problema eles tentam resolver e refletir se as soluções propostas se adéquam às realidades. Ou seja, transformar cada protocolo em uma ferramenta, e não em uma doutrina, é chave para o manejo das relações intercessoras que produzem o cuidado. 


\section{A perspectiva da micropolítica e do processo de trabalho em saúde}

\section{a) Atuação da equipe na coordenação do cuidado}

Segundo Merhy (2005) e Merhy e Cecílio (2003), o cuidado, nas organizações de saúde em geral, é, por sua natureza, necessariamente multidisciplinar, depende da conjugação do trabalho de vários profissionais. Mecanismos instituídos de dominação e de relações muito assimétricas de poder entre as várias corporações profissionais ocultam a imprescindível colaboração que deve existir entre os vários trabalhadores, como operadores de tecnologias de saúde, para que o cuidado aconteça. O cuidado, de forma idealizada, recebido/vivido pelo paciente, é somatório de um grande número de pequenos cuidados parciais que vão se complementando, de maneira mais ou menos consciente e negociada, entre os vários cuidadores que circulam e produzem a vida dos serviços de saúde. Assim, uma complexa trama de atos, de procedimentos, de fluxos, de rotinas, de saberes, num processo dialético de complementação, mas também de disputa, vai compondo o que entendemos como cuidado em saúde.

O cuidado à saúde dispensado pelas equipes pode ser decomposto em inúmeros outros atos diagnósticos e terapêuticos, realizados por vários trabalhadores diferentes, conforme o modelo de atenção e de gestão de produção do cuidado.

Para ilustrar este fato, basta imaginarmos os cuidados de um paciente com diabetes, internado com um quadro de descompensação, nos serviços que temos hoje em oferta para produzir esse cuidado. Além dos cuidados iniciais do plantonista, que o recebe e interna a partir do prontosocorro, ele receberá também cuidados da enfermagem, poderá ser visto, em algum momento, pelo cirurgião vascular, pelo cardiologista, pelo endocrinologista, pela nutricionista, pela assistente social e pela psicóloga. Além do mais, terá seu corpo escrutinado por uma bateria de exames, alguns deles bastante complexos, realizados em serviços diferentes e por profissionais distintos. Um dos grandes desafios do trabalho em saúde é conseguir coordenar adequadamente esse conjunto diversificado, especializado, fragmentado de atos cuidadores individuais, que resulte em uma dada coordenação do cuidado (Merhy, Cecilio, 2003), ao mesmo tempo em que deve-se mudar o sentido desse modelo de cuidado, tarefa que também depende da própria forma como se encara o lugar da LC como estratégia de gestão de novos modos de se produzir saúde.

Por isso, cabe refletir sobre a correlação do cuidado como o processo de gestão. Uma coisa é pensar o trabalho em equipe como somatório de ações específicas de cada profissional, como linha de montagem do tratamento da doença, papéis hierárquicos e rígidos; a outra é pensar arranjos institucionais, modos de operar a gestão do cotidiano sobre a micropolítica do trabalho que resultem em uma atuação mais solidária, articulando um grande número de trabalhadores envolvidos no cuidado. Nesta medida, o tema da integralidade do cuidado, passa, necessariamente, pelo aperfeiçoamento da coordenação do trabalho em equipe (Merhy, Cecílio, 2003).

Outro fator primordial consiste na compreensão do trabalho em saúde de forma integrada, incluindo a participação e os saberes de uma equipe multidisciplinar que garanta o cuidado integral. Articulando saberes, práticas, olhares diversos. E outro elemento consiste na garantia da formação adequada dos profissionais de saúde, investindo em educação e capacitação permanente.

Segundo Merhy e Cecílio (2003), o delicado processo de coordenação do cuidado se faz por meio de dois mecanismos principais. O primeiro deles é a criação de "pontes" ou pontos de contato entre as lógicas da profissão: médicos e enfermeiros e os outros profissionais têm de conversar para que o cuidado se realize. Uma coordenação "em ato", o encontro de práticas, de saberes. Torna-se desafiador construir uma coordenação mais horizontal, mais regular e "institucionalizada" entre os vários profissionais, centrada no cuidado. A própria lógica, em si, da produção do cuidado, e sua micropolítica, remete a uma forma mais transversalizada de operar o cuidado, integrada em uma rede mais ampla de serviços, composta de vários pontos, ou várias "estações". Os coordenadores de LC deverão ter a preocupação de buscar uma melhor articulação entre estas várias "estações cuidadoras". Isto vale para todas as linhas. A integralidade do cuidado é tarefa de rede de serviços (Merhy, Cecílio, 2003).

A participação dos trabalhadores como sujeitos do processo é essencial e vital, abrindo espaços de escuta, participação, definição conjunta de espaços decisórios, adesão ao projeto de melhoria 
da qualidade assistencial que seja centrado nas necessidades do usuário e forte responsabilização institucional pelo processo. Estes espaços decisórios destinam-se a: favorecer a melhor interação entre os trabalhadores das equipes e o estabelecimento de corresponsabilidade entre os atores envolvidos no ato de cuidar, discussão de protocolos adaptados aos usuários, definição de condutas e responsabilidades. Ações a serem operadas no espaço da gestão que a educação permanente possibilita.

\section{b) Vinculação e responsabilização do cuidador}

Sob a perspectiva da micropolítica, o acompanhamento do fluxo da LC pressupõe a responsabilização do cuidador pelo usuário. O consumo de "tecnologias duras" (exames, imagens, procedimentos) implicará o retorno ao "cuidador", que definirá sempre pela necessidade de novos procedimentos, ou pela instituição de determinada terapêutica. A figura do cuidador é central e pressupõe o uso intenso da "tecnologia leve" (dos saberes, da capacidade de decisão do profissional) e da tecnologia "leve-dura" (protocolos, que deverão ser adaptados pelo cuidador na singularidade do sujeito). Este é um espaço relacional pleno de subjetividades, implicando o encontro entre o usuário e o cuidador. Esse fluxo se faz sempre marcado por subjetividades, pelo encontro singular entre o profissional e o usuário. O usuário não faz esse percurso de forma impessoal, mecânica, desvinculada de sentimentos e impressões (Malta, Merhy, 2003; Merhy, 2002, 1997).

A dimensão cuidadora, produtora de tecnologias leves, relacionais, torna-se fundamental para ampliar a capacidade dos trabalhadores de lidarem com a subjetividade e com as necessidades de saúde dos usuários. Estes espaços de encontro são singulares para operar esta compreensão dos trabalhadores acerca das necessidades dos usuários, e portanto, com a produção de um cuidado integral à saúde (Feuerwerker, 2005; Merhy, Cecílio, 2003).

Os trabalhadores não são uma "caixa vazia", ao contrário, utilizam seus espaços de autonomia para agir como lhes parece correto, de acordo com seus valores e/ou interesses (Helman, 2003). Portanto, preservar a autonomia dos trabalhadores é essencial para ampliar a qualidade do cuidado, sua capacidade de decisão, de envolvimento, de compromisso e vínculo com o usuário (Feuerwerker, 2005).

O caminhar pela linha de cuidado pressupõe a existência de uma rede de serviços que suporte as ações necessárias, o projeto terapêutico adequado àquele usuário, que comandará o processo de trabalho e o acesso aos recursos disponíveis à assistência. Portanto, as pontes e os entrecruzamentos entre a macropolítica e a micropolítica atravessam todo o percurso da LC.

\section{c) Busca da produção da autonomia do usuário}

Além disto, outro elemento-chave consiste em fortalecer a capacidade de o usuário cuidar de si, o que vai muito além de um simples autocuidado protocolado dos portadores de DCNT, estimulando seu empoderamento, suas escolhas, suas opções. A sua autonomia é fundamental para fortalecer suas escolhas responsáveis, a sua qualidade de vida. E, por isso, devem-se revisar as estratégias de trabalho de grupo e de educação em saúde que vêm sistematicamente povoando nossas redes de saúde, que utilizam métodos ultrapassados que pouco contribuem para esses processos. Os caminhos clássicos de informações e educação tipo bancária devem ser substituídos, conforme já alertava há muito o educador Paulo Freire, em seus vários trabalhos e preleções (Freire, 1983).

Torna-se fundamental ganhar a implicação do usuário nas apostas de prevenção, controle e recuperação, para a obtenção de melhores resultados. Deve-se assegurar o acompanhamento regular e a participação do cliente. A DCNT é de longa duração e esta nova realidade nem sempre está clara para o paciente, sendo momento de tensão, angústia e contradições. Nem sempre está claro o conviver com o novo estado, o lidar com a doença, comorbidades, limitações e medos decorrentes.

Por outro lado, tampouco os profissionais de saúde têm claro as limitações de cada sujeito, e nem sempre os mesmos possuem formação para promover a ampliação de autonomia dos sujeitos, buscando a ampliação das suas habilidade para a autogestão da doenças crônicas. Torna-se necessário investir nos cuidadores para que incentivem abordagens compreensíveis e adaptadas à cultura do usuário, suas singularidades, limites, fortalezas e fraquezas (Taplin, 1998). Torna-se necessário, ainda, mapear redes sociais de apoio existentes na comunidade, família, que possam fortalecer esses processos cuidadores. Incentivar redes de solidariedade, trocas, apoios integrados. Além disto, o 
cuidador deve se disponibilizar para apoiar o processo de travessia, mostrando-se aberto e disponível para o usuário, à medida que ocorram necessidades e demandas. O que exige mudanças substanciais no modo de se construírem as redes de cuidado (Franco, 2006).

\section{Análise da LC}

A análise da LC possibilita: mapear os recursos disponíveis nos diversos segmentos da saúde, avaliar as tecnologias utilizadas para assistir o beneficiário, quanto ao tipo, fluxos, mecanismos de regulação, tentativas de negação de acesso, ações de vigilância à saúde, promoção, utilização dos recursos das clínicas especializadas.

Ao analisar o caminhar do usuário na linha, pode-se verificar se este fluxo está centrado no campo de necessidades dos usuários, determinado pelo suposto projeto terapêutico que lhe é indicado, a sua acessibilidade aos serviços, comodidade, segurança no atendimento, acompanhamento, tratamento, orientação e promoção, ou, ao contrário, se ocorre a fragmentação ou interrupção da assistência (Merhy, Onocko, 1997).

O esperado é um "caminhar" na rede de serviços que seja seguro, sem obstáculos, pois isto garantirá a qualidade da assistência. A "linha de produção do cuidado" não se encerra no momento em que é estabelecido o projeto terapêutico, ela deve continuar no acompanhamento deste usuário para garantir a integralidade do cuidado. Existem diversas etapas neste percurso (LC) que são microprocessos de trabalho específico, determinado pelos atos de cada produtor de serviços/ profissional de saúde envolvido. Cada microunidade produtiva (consultório médico, laboratório e outras) fornece insumos umas às outras, e é local de intensa possibilidade de análise no que se refere à configuração tecnológica do trabalho produzido, o que pode ser obtido por meio da análise das valises tecnológicas em operação, suas conformações e combinações (Merhy, 2002). Os processos existentes em cada etapa estarão integrados ou não, dependendo do modelo em curso (Malta et al., 2004).

$\mathrm{Na}$ análise deste percurso é importante identificar a fragmentação da LC, o que pode ocorrer em função de:

a) A ausência de ofertas de práticas de promoção e prevenção pode ser determinante do estímulo à entrada na rede de serviços. Exemplos simples, como o estímulo à prática da atividade física, a estruturação de grupos de acompanhamentos de hipertensos, diabéticos, idosos, vinculando clientelas específicas, e evitar consumos desnecessários de serviços. Estas práticas devem ser estimuladas pelos gestores do setor público, pelas operadoras de planos de saúde. Enquanto essa prática não for assentada em responsabilidade concreta, muitas ações assistenciais curativas mais complexas e desnecessárias serão praticadas.

b) Ausência de gestão e regulação dos processos - os gestores formais são os garantidores dos macroprocessos, sua atuação é definidora do planejamento e gestão da rede, articulação intersetorial, funcionamento da regulação, existência da rede de serviços, insumos, regulação de fluxos assistenciais, formação e capacitação dos trabalhadores no trabalho e, até mesmo, a priorização da agenda da integralidade do cuidado.

c) Deficiência da rede de serviços (insuficiência do apoio diagnóstico terapêutico), inexistência de ofertas específicas (alta complexidade, exames não cobertos), oferta insuficiente seja pelo número, seja pelas especialidades e/ou complexidade disponíveis.

d) Atitudes de desresponsabilização do cuidador, com: não vinculação, saber insuficiente, negação ou cerceamento de uso de tecnologias adequadas, retardo ou não fechamento do diagnóstico, não oferta de mecanismo de acolhida às demandas agudas. Quando não existe um "cuidador", ocorrem repetições de procedimentos desnecessários, tornando a atenção mais onerosa e ineficiente.

e) Atitudes de cerceamento ao acesso, dificultando a autorização de procedimentos essenciais à assistência, especialmente acesso a tecnologias e procedimentos de alta complexidade e custo.

f) Prestador com falta de insumos, perda de exames, qualidade questionável na prestação de assistência.

g) Definição de cuidador que articule todo o percurso da LC. Para evitar a fragmentação do cuidado, dever-se-ia operar em outro formato do modelo assistencial, comandado por um processo de trabalho 
cuidador, que oriente esse percurso. Quando isso não existe, o usuário faz o seu próprio caminhar pelas redes de serviços, induzindo consumo de procedimentos. Essa prática é altamente perversa, podendo levar a erros e indução ao consumo de procedimentos. Muitas vezes, só o usuário consegue recuperar a história da sua peregrinação, sendo o seu próprio "fio condutor" (Malta et al., 2004).

O grande desafio consiste em restabelecer uma nova prática, centrada no estímulo à promoção da saúde, prevenção e resolubilidade dos problemas de saúde do usuário, referenciada no vínculo e na responsabilização. Torna-se importante, aos gestores, públicos e privados, estimularem a prática da vinculação a cuidadores, mapeando certos grupos de risco (idosos, diabéticos, hipertensos), ou certos ciclos de vida. Estimulando os usuários a se vincularem a "cuidadores" por meio de práticas de cuidado centradas nas tecnologias leves de impacto para a produção dessa relação. Poderia se estimular que os cuidadores tivessem usuários cadastrados e fizessem acompanhamento sistemático, definindo projetos terapêuticos adequados a cada situação, estimulando a participação em grupos educativos de novo tipo (lembrando de novo Paulo Freire), o acompanhamento e monitoramento desses usuários com algum risco diferenciado.

No caso dos hipertensos, diabéticos e idosos com múltiplos fatores de risco: o acompanhamento da medicação de uso contínuo, a garantia do atendimento aos casos agudos, enfim, a garantia da continuidade do processo, o contato quando o retorno não foi cumprido, a informação sobre as intercorrências, possíveis internações, e de todo o processo assistencial (Malta et al., 2004).

A linha de cuidado pode ser acompanhada e monitorada, tomando-se eventos sentinelas, como marcadores dos eventos "atípicos" ou ruídos na cadeia de cuidado. O evento sentinela constitui-se evento não esperado e cuja detecção serve de alerta para determinado fato sob observação (Malta, Duarte, 2007; Rutstein, 1976).

Existem possibilidades de se monitorarem os resultados de uma população por meio dos Sistemas de Informação existentes, avaliando-se indicadores de processo, ou resultado. Além disto, coloca-se, então, o desafio de se implantar um sistema de informação (SI) baseado em informações individuais, que possibilite capturar dados dos usuários de risco de forma contínua, mapeando grupos e indivíduos prioritários e seus eventos adversos, como complicações, internações. Este monitoramento pressupõe a existência de um cuidador e da articulação da equipe. Existem sistemas de informações complexos, com prontuário eletrônico e monitoramento de indicadores e, outros simplificados, como as planilhas dos agentes comunitários de saúde, que cumprem o papel de alimentar as equipes com dados vitais. O essencial deste processo é que existam cuidadores que estejam atentos a estes processos e desenvolvam ações oportunas, especialmente quando sinais de alerta forem emitidos por estes sistemas (agudização, prescrição de medicação de urgência, procura à unidade de emergência, internação, outros).

As vantagens destes sistemas de informações clínicas seria a possibilidade de se identificarem subpopulações relevantes para atenção proativa, facilitando o planejamento de atenção individual, compartilhando informações com provedores e pacientes. Este tipo de SI se apoia no monitoramento e performance das equipes e do sistema.

\section{Conclusão}

Este ensaio toma, como exemplo, as DCNT, pela sua grande magnitude, mas os demais problemas de saúde, sejam as doenças infecciosas e outras, também se inserem no contexto da não responsabilização no processo terapêutico. Ou seja, a crise em saúde passa pelo modo de cuidar que não vincula, que não opera com as tecnologias leves produtoras de singularizações no cuidado e, ao mesmo tempo, de mútua construção terapêutica entre trabalhador e usuário. Portanto, as reflexões aqui apresentadas cabem também para as linhas de cuidado em geral, que precisam ser repensadas sob novas categorias.

No caso dos portadores de DCNT, as linhas de cuidado necessitam articular ações de proteção, promoção, vigilância, prevenção e assistência, voltadas para as especificidades de grupos ou necessidades individuais, permitindo não só a condução oportuna dos pacientes pelas diversas 
possibilidades de diagnóstico e de terapêutica, mas, também, uma visão global das suas condições de vida (Brasil, 2008).

A LC, nesta perspectiva, é centrada no campo de necessidades dos usuários e pressupõe: a existência do cuidador, o uso da tecnologia leve, o projeto terapêutico adequado, a existência da rede de serviços que suporte as ações necessárias, o acesso aos recursos assistenciais disponíveis, além da atuação nos determinantes sociais e no processo regulatório.

O cuidado integrado das DCNT prioriza o encadeamento de ações e, ao mesmo tempo, aponta a necessidade de integração de agendas por parte dos gestores, seja do ponto de vista da responsabilidade compartilhada entre esferas diferentes de governo, seja pela intersetorialidade que viabilize ações fora do setor saúde. Diante da epidemia de DCNT cabe agregar tecnologias orientadas e preparadas para a abordagem de processos de adoecimento de mais longo prazo e de causalidade complexa, na qual se articulam diferentes fatores individuais, coletivos, sociopolíticos, culturais, históricos e econômicos, e ação integrada com outros setores.

A análise da situação de saúde de DCNT e seus fatores de risco e proteção exige tecnologias de organização do processo de trabalho que retomem o protagonismo do setor sanitário no debate das políticas de desenvolvimento e organização econômica e social do país, destacando o seu papel de advocacy na garantia de direitos de cidadania à população.

Reorientar os modelos de atenção à saúde requer a compreensão da situação de saúde de dado local para poder atuar na realidade de saúde. Em se tratando das DCNT, elas têm sua especificidade, especialmente no que diz respeito à qualidade de vida das pessoas e de suas famílias.

Uma abordagem focada na promoção deve incluir: fatores de risco e doenças já instaladas - como diabetes e hipertensão; ações educativas e estímulo a mudanças no estilo de vida; estratégias de adesão ao tratamento medicamentoso; ações produzidas por equipe multidisciplinar; incorporação de outros profissionais de saúde; empoderamento do indivíduo para o autogerenciamento das suas doenças e dos seus riscos - autonomia.

A ação cuidadora implica mecanismos de responsabilização - por parte de equipe, gestores públicos, operadoras de planos de saúde - que resultem em ação integral, na qual não ocorram a interrupção e a segmentação do cuidado; o que exige um sistema único de saúde atuando coerentemente em todos os frontes de produção de práticas de saúde, públicos e privados.

\section{Colaboradores}

Deborah Carvalho Malta participou da concepção teórica, elaborou a versão inicial e final do texto; Emerson Elias Merhy participou da concepção teórica, revisou e trabalhou na versão final do manuscrito.

\section{Referências}

BAREMBLITT, G. Compêndio de análise institucional e outras correntes: teoria e prática. 3.ed. Rio de Janeiro: Rosa dos Ventos, 1996.

BRASIL. Secretaria de Vigilância em Saúde. Diretrizes para a promoção, prevenção e controle de DCNT. Brasília: Ministério da Saúde, 2008.

CECÍLIO, L.C.O. Uma sistematização e discussão de tecnologia leve de planejamento estratégico aplicada ao setor governamental. In: MERHY, E.E.; ONOKO, R. (Orgs.). Agir em saúde, um desafio para o público. São Paulo: Hucitec, 1997. p.151-67.

(Org.). Inventando a mudança na saúde. São Paulo: Hucitec, 1994.

DONNANGElO, M.C.F.; PEREIRA, L. Saúde e sociedade. São Paulo: Duas Cidades, 1976.

FEUERWERKER, L. Modelos tecnoassistenciais, gestão e organização do trabalho em saúde: nada é indiferente no processo de luta para a consolidação do SUS. Interface Comunic., Saude, Educ., v.9, n.18, p.498-506, 2005. 
FRANCO, T.B. As redes na micropolítica do processo de trabalho em Saúde. In: PINHEIRO, R.; MATTOS, R.A. (Orgs.). Gestão em redes. Rio de Janeiro: LAPPIS-IMS/UERJ-Abrasco, 2006. p.459-73.

FRANCO, T.B.; MAGALHÃES JÚNIOR, H.M. A integralidade na assistência à saúde. In: MERHY et al. (Orgs.). O trabalho em saúde: olhando e experenciando o SUS no cotidiano. São Paulo: Hucitec, 2003. p. 125-33.

FREIRE, R.C. As ações programáticas no projeto saúde todo dia: uma das tecnologias para a organização do cuidado. Dissertação (Mestrado) - Faculdade de Ciências Médicas, Universidade Estadual de Campinas, Campinas. 2005.

FREIRE, P. Educação com prática de liberdade. Rio de Janeiro: Paz e Terra, 1983.

HELMAN, C. Cultura, saúde e doença. Porto Alegre: Artmed, 2003.

MALTA, D.C.; DUARTE, E.C. Causas de mortes evitáveis por ações efetivas dos serviços de saúde: uma revisão da literatura. Cienc. Saude Colet., v.12, n.3, p.319-30, 2007.

MALTA, D.C. et al. A Política Nacional de Promoção da Saúde e a agenda da atividade física no contexto do SUS. Epidemiol. Serv. Saude, v.18, n.1, p.79-86, 2009.

A construção da vigilância e prevenção das doenças crônicas não transmissíveis no contexto do Sistema Único de Saúde. Epidemiol. Serv. Saude, v.15, n.15, p.47-65, 2006.

Perspectivas da regulação na saúde suplementar diante dos modelos assistenciais. Cienc. Saude Colet., v.9, n.2, p.433-44, 2004.

MALTA, D.C.; MERHY, E.E. A micropolítica do processo de trabalho em saúde - revendo alguns conceitos. Rev. Mineira Enferm., v.7, n.1, p.61-6, 2003.

MERHY, E.E. Gestão da produção do cuidado e clínica do corpo sem órgãos: novos componentes dos processos de produção do cuidado em saúde. 2007. Disponível em: <http://www.uff.br/saudecoletiva/professores/merhy/artigos-25.pdf>. Acesso em: 14 mar. 2009.

Integralidade: implicações em xeque. 2005. Disponível em: <http://www.uff.br/ saudecoletiva/professores/merhy/artigos-13.pdf>. Acesso em: 14 mar. 2009.

Saúde: a cartografia do trabalho vivo. São Paulo: Hucitec, 2002.

. O SUS e um dos seus dilemas: mudar a gestão e a lógica do processo de trabalho em saúde (um ensaio sobre a micropolítica do trabalho vivo). In: FLEURY, S. (Org). Saúde e democracia, a luta do CEBES. São Paulo: Lemos, 1997. p.125-41.

MERHY, E.E.; CECÍLIO, L.C.O. A integralidade do cuidado como eixo da gestão hospitalar. Campinas: Unicamp, 2003. (mimeogr.).

MERHY, E.E.; ONOCKO, R. Agir em saúde: um desafio para o público. São Paulo: Hucitec, 1997.

MERHY, E.E.; CECÍLIO, L.C.O.; NOGUEIRA, R.C. Por um modelo tecno-assistencial da política de saúde em defesa da vida: contribuição para as conferências de saúde. In: CONFERÊNCIA NACIONAL DE SAÚDE, DESCENTRALIZANDO E DEMOCRATIZANDO O CONHECIMENTO, 9., 1992, Brasília. Cadernos... Brasília, 1992. p.91-6. v.1.

MONTEIRO, C.A. et al. Population-based evidence of a strong decline in the prevalence of smokers in Brazil (1989-2003). Bull. World Health Org., v.85, n.7, p.527-34, 2007.

RUTSTEIN, D.D. et al. Measuring the quality of medical care. N. Engl. J. Med., v.294, n.11, p.582-8, 1976. 
TAPLIN, S. et al. Putting population-based care into practice: real option or rhetoric? J. Am. Board Fam. Pract., v.11, n.2, p.116-26, 1998.

VASCONCELOS, L.C. Introdução à regulação à saúde suplementar. In: AGÊNCIA NACIONAL DE SAÚDE - ANS. Introdução à regulação à saúde suplementar: histórias e práticas. Rio de Janeiro: Agência Nacional de Saúde Suplementar, 2008. p.18-28.

WORLD HEALTH ORGANIZATION - WHO. Preventing chronic diseases: a vital investment. Switzerland, 2005. Disponível em: <http://www.who.int/chp/chronic disease_report/en>. Acesso em: 22 mar. 2010.

MALTA, D.C.; MERHY, E.E. El trayecto de la línea del cuidado bajo la perspectiva de las enfermedades crónicas no transmisibles. Interface - Comunic., Saude, Educ., v.14, n.34, p.593-605, jul./set. 2010.

El trabajo caracteriza la línea del cuidado (LC) según las perspectivas micro y macro políticas o de gestión. Se toma el ejemplo de las Enfermedades Crónicas No Transmisibles (ENT), por su magnitud y por sus características: enfermedad de larga duración, demandando intensa actuación de cuidadores, proyectos terapéuticos, acceso a los servicios y acciones integradas. El trabajo discute la perspectiva de la LC centrada en el campo de necesidades de los usuarios y presupone la existencia del cuidador, uso de tecnología blanda, proyecto terapéutico adecuado, existencia la red de servicios que soporte las acciones necesarias, el acceso a los recursos asistenciales disponibles, además de la actuación en los determinantes sociales y en el proceso regulativo. Se discute el desarrollo de políticas de promoción, prevención, vigilancia y asistencia de DCNT, articulando acciones en el campo de la micro-política y de la macro-política, integrando intervenciones en los determinantes sociales, legislación, tecnologías e instrumentos.

Palabras clave: Línea del cuidado. Autonomía. Micro-política. Trabajo en salud. Enfermedades crónicas no transmisibles. 
